\title{
Analysis on Reading and Writing Theory of English Reading Model
}

\author{
$\operatorname{Min} \mathrm{Li}$ \\ Chengyi University College, Jimei University, Xiamen, Fujian, 361021
}

Keywords: reading and writing, English reading, learning level

\begin{abstract}
As a compulsory language subject in Chinese teaching, English should be read and written with equal emphasis on learning. On the one hand, students can read out accurately and standardly. On the other hand, students are required to skillfully spell out. In this way, students can read English, and the level can be improved. This paper analyzes the current situation of English reading and writing teaching in high school, and proposes a feasible measure based on literacy mode in high school English reading teaching mode.
\end{abstract}

\section{Introduction}

English teaching has always been an extremely important part of high school teaching. The significance of English teaching is not only that it can expand the knowledge of students, broaden the horizons of students, and more importantly, it can help students develop a new mode of thinking. Therefore, how to improve students' English learning quality has become a key issue in the current education circle. The significance of discussing this issue is to change the way students think, broaden their horizons and improve their academic performance. The reading and writing combination of reading and writing has the superiority that other teaching modes do not have. For example, it can better teach students in accordance with their aptitude, optimize the classroom teaching structure, and help students improve their academic performance. Therefore, how to further analyze the reading teaching mode of high school English literacy is also a hot topic.

\section{Status of English Teaching}

Writing teaching has always been a more important part of English teaching. Its importance is not only reflected in the proportion of the volume, but more importantly, writing can reflect a student's thinking and literary qualities. Through continuous reform and development in recent years, the level of English writing teaching in high school has been greatly improved, but there are still shortcomings in achieving achievements, such as the content of teaching is too boring, the thinking mode of students is too single, vocabulary and grammar There are a lot of errors in the aspect. So how to further solve these problems is a key issue that teachers should think about. Like writing teaching, in recent years, English reading teaching has also made a series of progress, but it is undeniable that English reading teaching still has shortcomings, which is mainly reflected in the fact that the teaching content is too rigid, and the teaching style can not really stimulate The students' interest in learning, the teacher's lack of expansion of the students' classroom content, and because of the high scores of reading in the English test, many high school English reading teaching is more inclined to test the teaching, can not really improve the students' reading level.

At this stage, high school English reading teaching has made rapid development, but there are still drawbacks in English reading teaching. These drawbacks are mainly due to the fact that high school English teaching content is too rigid. Traditional teaching style teaching methods can not stimulate high school students' English learning enthusiasm. English teachers only explain according to textbooks, and lack of extracurricular development of English knowledge. Because English reading has a higher proportion of English exam-oriented education, many high-school English teachers tend to read English for reading. For example, teachers require students to memorize words and grammar in English teaching. And inform the students when reading the explanation. This is the key point of the exam must be written down, never explain the knowledge 
about the exam, so that students can only learn mechanically, do not understand the knowledge of English culture can not be confused, so read for the exam The teaching method can't really improve the students' English reading level effectively.

\section{The Construction of English Reading Teaching Mode Based on Literacy Mode}

In the deep understanding stage, the main content of teaching is to guide students to learn different text content, deepen their understanding of ideas and connotations, and input reading materials. Among them, what needs to be understood includes language form and article content as well as text style. Reading is the basis of writing, and the ability to write should be cultivated and improved on the basis of reading. Therefore, in teaching, teachers should improve their ability to use language to express their thoughts through a certain amount of reading, familiarity with language points, expanding knowledge, and learning writing skills such as slogans and layouts. (2) Grasping the characteristics-- Grasping the characteristics of the text, the language input internalization learners receive and convey information in the communication, not only pay attention to the meaning expressed by the other party, but also pay attention to accurately and decently express their meaning, input $\rightarrow$ Feedback $\rightarrow$ Adjustment $\rightarrow$ Re-enter $\rightarrow$ Output, etc. Complete the reception and expression of meaning. On the basis of an in-depth understanding of the text, it is necessary to accurately grasp the characteristics of the text chapter. Among them, on the one hand, it is a "meaning feature", on the other hand, it is a discourse feature. Internalization of language input is achieved after grasping the chapter features. After writing some of the articles given, you should compare some essays, find out the gaps, and then practice, which not only encourages students to consolidate the knowledge they have learned in time, but also exercise their perseverance and study perseverance. English composition is also very helpful. In the output stage, students need to perform certain writing training to help them better consolidate the knowledge and skills they have learned, test the English reading effect, and improve their language skills. In the process of constructing the read-write mode in this paper, this stage is divided into three detailed steps, which are read and consolidated according to the layer-by-layer way to promote language output. Among them, the first step is to rewrite after reading--rethinking the reading process; the second step is to read the imitation after reading--to consolidate the input effect; the third step is to write after reading--to promote language output.

\section{Strategies for High School English Reading Teaching Mode Based on Literacy Mode}

The high school English reading teaching mode based on literacy puts forward higher requirements for teachers in English teaching. It requires teachers to have certain teaching enthusiasm in English teaching. For English language teaching, the enthusiasm of English teachers is to promote students' English. Important conditions for learning interest. Teachers' enthusiasm for learning will infect students with unknowingly, thus promoting students' self-learning in English. The classroom language of English teachers should be easy to understand, especially in reading teaching, so that students can fully understand the content of the teacher's explanations while reading and learning in the classroom, thus improving the students' high school English learning.

The high school English reading teaching mode based on literacy requires high school English teachers to teach students according to their differences, so as to ensure that each student's English learning level can be improved. To teach students in accordance with their aptitude, teachers are required to have a comprehensive and meticulous grasp of the actual situation of each student. This will greatly help students to know themselves objectively. At the same time, English teachers should learn to give appropriate awards to students. This way can stimulate students' enthusiasm for English learning and stimulate students' initiative in learning. Classroom evaluation in English teaching is especially important for students. Classroom evaluation can make students recognize the inadequacies of their own English learning, and find their own strengths, so as to regain confidence and clear the direction and goal of learning. Therefore, high school English teachers should develop evaluation criteria according to different people in the classroom evaluation, so that students can 
better understand their own advantages and disadvantages. At the same time, such evaluation criteria can be more specific to students' English learning. Accurate understanding.

Classroom teaching is the specific implementation of the teaching classroom objectives, because the establishment of teaching objectives is not the same, which requires teachers to stratify the classroom teaching content to ensure the realization of teaching objectives. High school English teachers should be clear about what is necessary to learn and what is the content of teaching expansion, thus helping students to focus on learning. Teachers should pay attention to asking students questions in classroom teaching, and can ask questions according to the differences of students' main body. This approach satisfies the learning needs of students at different levels, and promotes the communication between teachers and students and improves students' learning. enthusiasm.

The high school English reading teaching mode based on literacy requires teachers to establish a student-centered teaching mode in teaching. The traditional high school English teaching is mostly the teacher's leading classroom teaching, and the students passively accept, so the students' learning enthusiasm is greatly suppressed. Over time, students lose their interest in learning, and even some students will lose the ability to learn English independently. Therefore, the high school English reading mode based on literacy requires teachers to be student-centered in English classroom teaching and to carry out teaching according to the subjective differences of students. Such teaching can greatly enhance students' interest in English learning and self-learning. At the same time, the self-conscious learning habits of students' English learning can ensure that students can adjust their progress and content according to their actual situation, so as to truly teach students in accordance with their aptitude.

In addition to copying and rewriting, students can also be instructed to write after reading. In the post-reading writing stage, the choice is to complete the teaching by guiding the students to read and write and freely write. First, instruct students to read and write. By continuing to write, the students are led to divergent thinking and writing according to the previous text. To further train students' abilities in language use and paragraph arrangement, as well as to maintain a coherent and consistent context. In the process of writing, the teacher can guide the students to carry out the next step of writing based on mastering the structure and content of the original text, as well as the emotional tone and language style. In the process of writing, the students are guided to divergent thinking, develop imagination, and constantly enrich the original text content according to their own understanding. In the sequel writing stage, the students use the original text as a reference, and under certain restrictions, they write according to certain conditions, and the writing difficulty is relatively small. After completing the continuation, you can further improve the difficulty and guide students to freelance writing. In the free writing stage, students can no longer be bound and restricted by the previous texts, and can freely play with their own understanding and ideas as well as mastering writing skills. Through different understandings, different opinions, different writing skills, and other writing skills. In writing, students can describe their own ideas and opinions, and have a high degree of freedom. But there may be some difficulties in language expression. Teachers can provide help and guidance in a timely manner, guiding them to use the various rounds of expression they have learned to write. Through this stage of practice, students can make full use of the various language knowledge and skills they have learned and mastered before, and realize the output of knowledge.

\section{Conclusion}

High school English teachers should fully understand the actual situation of English teaching in China, improve the level of English reading and writing teaching, and analyze the status quo of English writing and reading in high school in China, instead of talking on paper, which requires teachers to teach. Find problems in time and solve them in time. The reform of the new curriculum in high school English is not just a slogan. Its realization requires the continuous efforts of high school English teachers in China, and the effective teaching content and methods in teaching. In the high school English reading teaching, teachers explore the feasible way of reform according to the 
practical teaching mode. At the same time, they actively implement the high school English reading teaching concept with equal emphasis on reading and writing, promote the improvement of English learning ability of high school students, and improve students' comprehensive quality. The road to high school English education reform has a long way to go and requires the top-down efforts of high school English teachers in China.

\section{References}

[1] Zhu Wenguang. Reading and Reading in High School English Reading and Reading Mode [J]. Middle School Students English (Foreign Language Teaching and Research), 2015(2): 29-29.

[2] He Liqun. Exploring the Reading and Writing Model of Reading, Reading and Reading in High School English [J]. Curriculum Education Research, 2015(7): 112-113.

[3] Wu Jianzhen. Exploring the Reading and Writing Teaching Model of High School English Reading Based on Reading and Writing [J]. Reading and Writing (teaching and research edition), 2015(15): 198-198.

[4] Wang Xiufeng. Reading and Teaching Model of High School English Reading Based on Reading and Writing [J]. Middle School Students English (Foreign Language Teaching and Research), 2015(2): 42-42.

[5] Wang Xilian. Reading and reading in high school English reading based on reading and writing [J]. Feelings, 2015(23): 39. 